\title{
Mathematical simulation of heat transfer in surface soil layer at forest fire influence in three-dimension statement
}

\author{
Nikolay V. Baranovskiy and Alexander E. Nee \\ National Research Tomsk Polytechnic University, Institute of Power Engineering, 634050 Tomsk, \\ Russia
}

\begin{abstract}
Mathematical simulation of non-stationary conductive heat transfer in volume with the local centre of ignition is spent. Fields of temperatures during the different periods of time on soil section are obtained. The problem is considered in three-dimensional statement. It is used finite difference method to decision of a problem. Results of the comparative analysis of the decision of two-dimensional and three-dimensional models are presented.
\end{abstract}

\section{Introduction}

Mathematical model [1] is developed for research of pyrogenic influences on soil from forest fires $[2,3]$. One of essential assumptions in that work is uses of one-dimensional model. Actually considered process of heat transfer has spatial character.

Besides theoretical researches of thermal influence of forest fires on soil there is a set of experimental works $[4,5]$. But it is necessary to notice, that such kind of research demands considerable resources and time, and in case of natural modelling of a fire, by an artificial burning out of forest fuels [6, 7], the requirement to safety precautions increases repeatedly.

Mathematical modelling is given to methods not enough attention at the decision of such problems, as heat transfer in soil layers at influence of the local centres of ignition. As have shown works [4, 5], numerical results concerning simple models will well be co-ordinated with the received data during experiments.

The work purpose is numerical research of heat transfer process in soil layers at influence of the local centre of ignition in three-dimensional statement.

\section{Physical and mathematical statement}

The layer of earth is considered as two-layer system [8], in which zones rich with organic chemistry (the top horizon by thickness of $5 \mathrm{~cm}$ ) and clay (the bottom horizon in the thickness of $5 \mathrm{sm}$ ) can be allocated. The heat transfer in the subsequent layers in work is considered by means of statement of boundary conditions of $3 \mathrm{rd}$ sort with use of factor of a heat transfer. It is necessary, that heat transfer to system "clay - organic layer - forest fuel-air" is carried out only at the expense of the heat conductivity

This is an Open Access article distributed under the terms of the Creative Commons Attribution License 4.0, which permits unrestricted use, distribution, and reproduction in any medium, provided the original work is properly cited. 


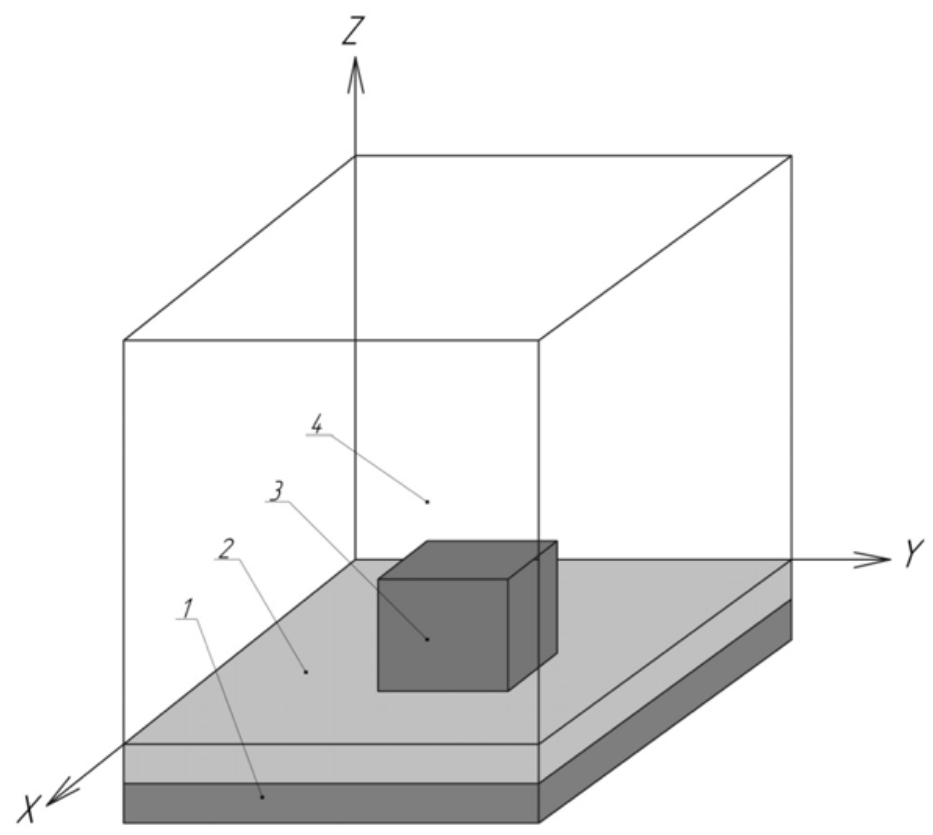

Figure 1. The scheme of decision area: 1 - clay; 2 - upper soil; 3 - forest fuel layer; 4 - air.

mechanism. The modelling soil without a binding to concrete type of soils [9] is considered. The decision area is presented by four layers: clay, a layer enriched by organic chemistry, forest fuel layer and air over forest fuel layer. On border of section of layers boundary conditions of 4th sort are exposed. On border of settlement area not indignant values of temperature (temperature in the heart of soil and in air accordingly on the bottom and top border) taking into account factors of a heat transfer are set. In forest fuel layer the area of the raised temperature corresponding to the centre of ignition is set. For forest fuel layer process of its thermal decomposition is considered. Gas-phase processes in air layer in the given version of mathematical model it is neglected. The decision area is presented on Fig. 1.

In such statement investigated process is described by the equations of heat conductivity for each element of area of the decision.

The equation of heat conductivity for clay:

$$
\rho_{1} c_{1} \frac{\partial T_{1}}{\partial t}=\lambda_{1} \cdot\left(\frac{\partial^{2} T_{1}}{\partial x^{2}}+\frac{\partial^{2} T_{1}}{\partial y^{2}}+\frac{\partial^{2} T_{1}}{\partial z^{2}}\right) .
$$

The equation of heat conductivity for a layer rich with organic chemistry:

$$
\rho_{2} c_{2} \frac{\partial T_{2}}{\partial t}=\lambda_{2} \cdot\left(\frac{\partial^{2} T_{2}}{\partial x^{2}}+\frac{\partial^{2} T_{2}}{\partial y^{2}}+\frac{\partial^{2} T_{2}}{\partial z^{2}}\right) .
$$

The equation of heat conductivity for forest fuel layer:

$$
\rho_{3} c_{3} \frac{\partial T_{3}}{\partial t}=\lambda_{3} \cdot\left(\frac{\partial^{2} T_{3}}{\partial x^{2}}+\frac{\partial^{2} T_{3}}{\partial y^{2}}+\frac{\partial^{2} T_{3}}{\partial z^{2}}\right)+q_{p} k_{p} \rho_{3} \varphi \exp \left(-\frac{E_{1}}{R T_{3}}\right) .
$$

The equation of heat conductivity for air:

$$
\rho_{4} c_{4} \frac{\partial T_{4}}{\partial t}=\lambda_{4} \cdot\left(\frac{\partial^{2} T_{4}}{\partial x^{2}}+\frac{\partial^{2} T_{4}}{\partial y^{2}}+\frac{\partial^{2} T_{4}}{\partial z^{2}}\right) .
$$


Table 1. Values of temperatures in an axis direction $\mathrm{z}$ in the top layer of earth for two-and three-dimensional cases at the moment of time $\mathrm{t}=600$ seconds (spring season).

\begin{tabular}{|l|l|l|}
\hline Coordinate, $\mathrm{z}, \mathrm{M}$ & 2D statement, T,K & 3D statement, T,K \\
\hline 0,1 & 277,4792 & 277,4791 \\
\hline 0,11 & 277,7693 & 277,7693 \\
\hline 0,12 & 278,4617 & 278,4615 \\
\hline 0,13 & 280,2443 & 280,2439 \\
\hline 0,14 & 285,0561 & 285,055 \\
\hline 0,15 & 297,2049 & 297,2018 \\
\hline 0,16 & 324,6204 & 324,6131 \\
\hline 0,17 & 378,8409 & 378,825 \\
\hline 0,18 & 471,4931 & 471,4627 \\
\hline 0,19 & 606,4977 & 606,446 \\
\hline 0,2 & 772,2649 & 772,1871 \\
\hline
\end{tabular}

The kinetic equation for forest fuel layer:

$$
\rho_{3} \frac{\partial \varphi_{3}}{\partial t}=-k_{p} \rho_{3} \varphi \exp \left(-\frac{E_{1}}{R T_{3}}\right) .
$$

Entry conditions for the Eqs. (1)-(5) look like:

$$
T_{1}(x, y, z, 0)=T_{c} ; T_{2}(x, y, z, 0)=T_{o l} ; T_{3}(x, y, z, 0)=T_{l s} ; T_{4}(x, y, z, 0)=T_{a} ; \varphi(0)=\varphi_{0} .
$$

Boundary conditions for the Eqs. (1)-(5) look like: On external borders of air:

$$
T=T_{u n} ;
$$

On the bottom border of a plane, perpendicular axis Z:

$$
K_{1}\left(T_{1}-T_{b}\right)=\lambda_{1} \frac{\partial T_{1}}{\partial y} .
$$

On borders of interface of layers:

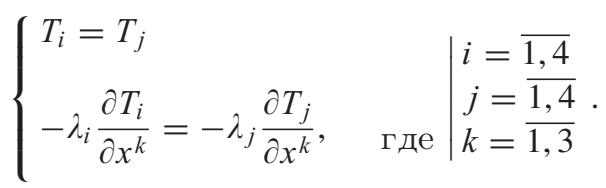

Where $T_{i}, \rho_{i}, c_{i}, \lambda_{i}$ - temperature, density, heat capacity, heat conduction ( 1 - clay layer, 2 - upper soil layer with organic matter, 3 - forest fuel layer, 4 - air); $q_{p}$ - heat effect of the thermal decomposition reaction of forest fuel; $k_{p}$ - pre exhibitor of the thermal decomposition reaction of forest fuel; $E_{1}$ - activation energy of the thermal decomposition reaction of forest fuel; $R$ - absolute gas constant; $\phi$ - inclusion volume fraction of dry organic matter of forest fuel; $\mathrm{K}_{1}$ - heat transfer coefficient; $\mathrm{x}, \mathrm{y}, z-$ spatial co-ordinates. $t$ - temporal coordinate.

The Eqs. (1)-(4) with corresponding initial and boundary conditions are solved by a method of final differences on a uniform grid [10]. For approximation of the equations of heat conductivity Samarskiy locally one-dimensional scheme [10] is used. One-dimensional difference analogues are solved by a marshed method [10]. Nonlinearity in the Eq. (3) was resolved by a method of simple iteration [10].

Following initial data are used: $\rho_{1}=1330 \mathrm{~kg} / \mathrm{m}^{3} ; \rho_{2}=1070 \mathrm{~kg} / \mathrm{m}^{3} ; \rho_{3}=500 \mathrm{~kg} / \mathrm{m}^{3} ; \rho_{4}=$ $0.03 \mathrm{~kg} / \mathrm{m}^{3} ; c_{1}=801 \mathrm{~J} /(\mathrm{kg} \cdot \mathrm{K}) ; c_{2}=976 \mathrm{~J} /(\mathrm{kg} \cdot \mathrm{K}) ; c_{3}=1400 \mathrm{~J} /(\mathrm{kg} \cdot \mathrm{K}) ; c_{4}=1200 \mathrm{~J} /(\mathrm{kg} \cdot \mathrm{K}) ; \lambda_{1}=$ $0.84 \mathrm{~W} /(\mathrm{m} \cdot \mathrm{K}) ; \lambda_{2}=0.5 \mathrm{~W} /(\mathrm{m} \cdot \mathrm{K}) ; \lambda_{3}=0.102 \mathrm{~W} /(\mathrm{m} \cdot \mathrm{K}) ; \lambda_{4}=0.1 \mathrm{~W} /(\mathrm{m} \cdot \mathrm{K}) ; q_{p}=1000 \mathrm{~J} / \mathrm{kg} ;$ $k_{p}=3.63 \cdot 10^{4} 1 / \mathrm{s} ; E_{1} / R=9400 \mathrm{~K} ; \varphi_{0}=1 ; K_{1}=20 \mathrm{~W} /\left(\mathrm{m}^{2} \cdot \mathrm{K}\right)$. 


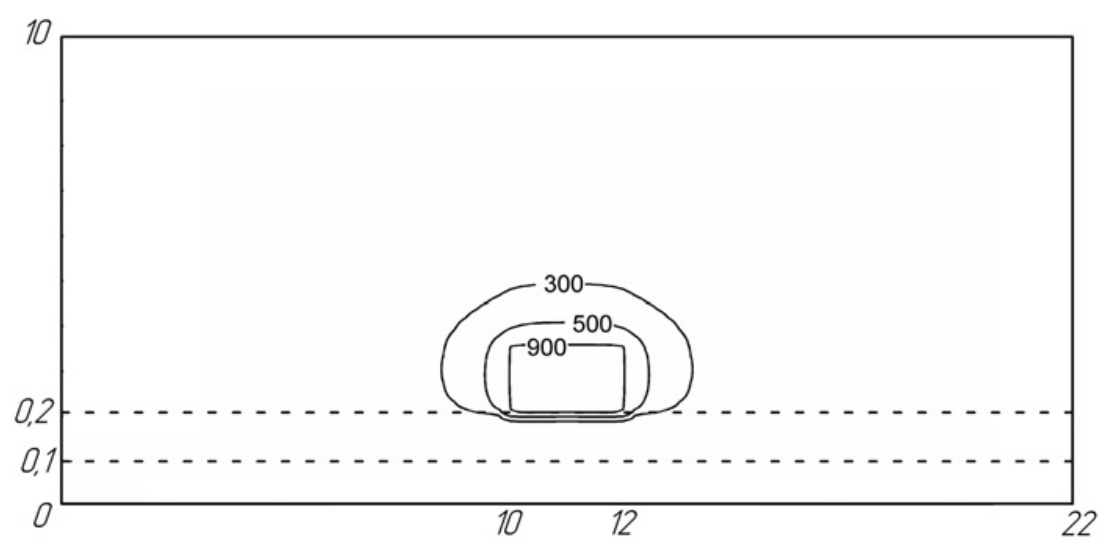

a)

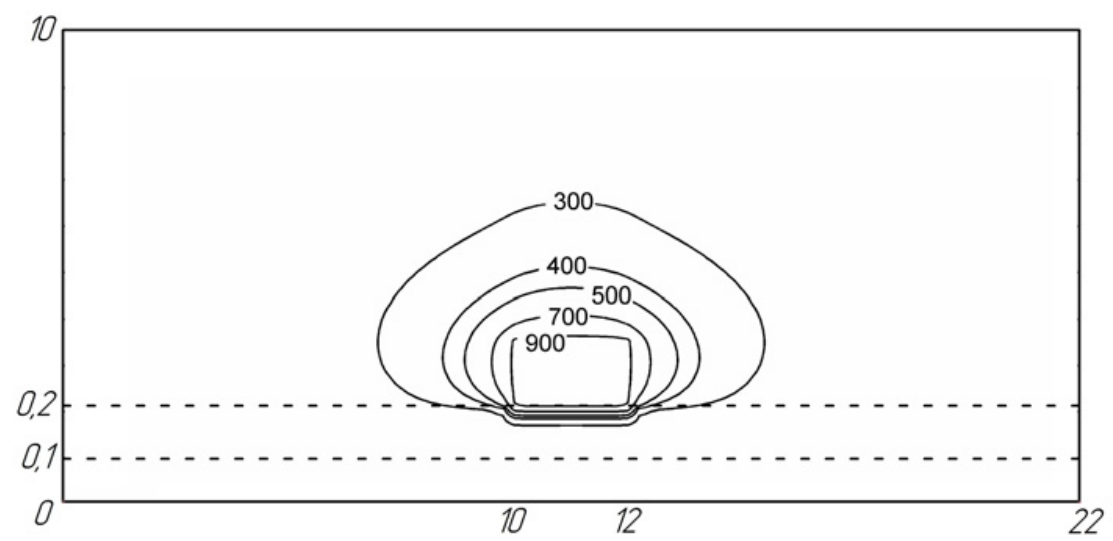

b)

Figure 2. Temperature distribution in section $x=11$ metres during time moments: $t=60$ seconds $(a)$; $t=$ 300 seconds (b).

\section{Results and discussion}

Results of numerical modelling are presented on Fig. 2 and Fig. 3. The sizes on axes of co-ordinates are postponed in metres, without scale. Initial values of temperature of a surface of soil, air and soil layers were set on the basis of help data. In the future use of more detailed mathematical models according to not indignant temperature profiles in soil on vertical co-ordinate is possible [11].

Apparently from Fig. 2 and Fig. 3, at short influence of the centre of forest fire authentic distinctions in soil temperature are appreciable on depth of $1-1,5 \mathrm{~cm}$ from an interface of environments "soil-forest fuel". In soil in a layer rich with organic chemistry on depth of $1 \mathrm{sm}$ environment gets warm over $100{ }^{\circ} \mathrm{C}$ and probably high-temperature evaporation of a soil moisture $[12,13]$. In the top centimetric soil layer probably its charring and pyrolysis of the vegetation residues.

At more long influence of the centre of forest fire authentic distinctions in soil temperature are appreciable on depth of 4-5 cm from an interface of environments "soil-forest fuel". In soil in a layer rich with organic chemistry on depth of 2-2,5 cm environment also gets warm over $100{ }^{\circ} \mathrm{C}$ and probably high-temperature evaporation of a soil moisture $[12,13]$. In the top two-centimetric soil layer probably its charring and intensive pyrolysis of the vegetation residues. 


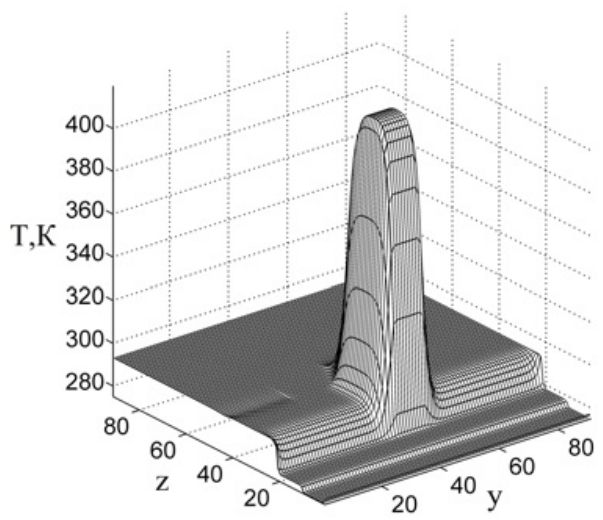

a)

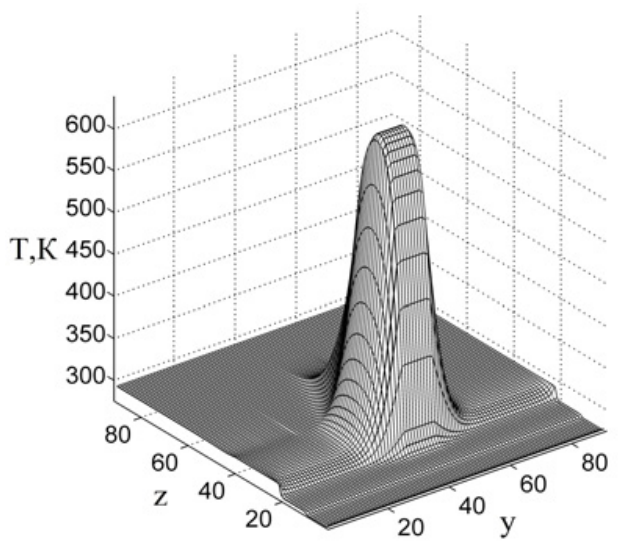

b)

Figure 3. Temperature distribution in section $x=8$ metres during time moments: $t=60$ seconds $(a)$; $t=$ 300 seconds (b). Points on axes $\mathrm{z}$ and $\mathrm{y}$ - the conditional co-ordinates answering to numbers of knots of difference mesh on decision area.

On the basis of comparison of temperatures in two- and three-dimensional cases it is possible to draw a conclusion on their practically full conformity (the difference makes no more than $0,1 \mathrm{~K}$ ). Hence, use of two-dimensional models is admissible at the decision of such problems, that also will allow to develop high efficiently algorithms [14] for geomonitoring systems [15-17].

\section{Conclusion}

For the first time the simple three-dimensional mathematical model of an estimation of influence of thermal modes of forest fires on surface layers of soil is presented. The two-layer structure of soil was considered. It is established, that considerable changes of temperature of soil occurs only in an organic layer. It will lead to considerable influence on functioning of microbiogeocenosis and soil properties $[18,19]$.

Temperature distributions in system "clay - organic layer - forest fuel - air" during the various moments of time are obtained. The obtained data can be used for an estimation of borders of influence of seats of forest fire on functioning of microbiogeocenosis in geomonitoring systems [15-17] including forest fire prediction methods based on mathematical models such as [20].

\section{References}

[1] N.V. Baranovskiy, R.M. Toychuev, Butlerovskie soobshcheniya, 34, 136 (2013) (In Russian)

[2] N.V. Baranovskiy, Matematicheskoe modelirovanie naibolee veroyatnikh scenariev $i$ usloviy vozniknoveniya lesnikh pozharov. Diss. ... Cand. fiz.-mat. nauk. (2007) (In Russian)

[3] G.V. Kuznetsov, N.V. Baranovskiy, Prognoz vozniknoveniya lesnikh pozharov $i$ ikh ecologicheskikh posledstviy (2009) (In Russian)

[4] L. DeBano, Journal of Hydrology, 231-232, 195 (2000)

[5] T. Iglesias, V. Cala, J. Gonzalez, The Science of the Total Environment, 204, 89 (1997)

[6] N.V. Baranovskiy, A.V. Zaharevich, V.I. Maksimov, Khimicheskaya fizika i mezoskopiya, 14, 175 (2012) (In Russian) 
[7] A.V. Zaharevich, N.V. Baranovskiy, V.I. Maksimov, Ecologicheskie sistemy i pribory, 7, 18 (2012) (In Russian)

[8] C. Matthews, F. Cook, J. Knight, R. Braddock, Australian Journal of Soil Research, 43, 945 (2005)

[9] A. Dukarev, Landscape aspects of taiga soil formation in Western Siberia (2005) (In Russian)

[10] P. Majumdar, Computational Methods for Heat and Mass Transfer (2005)

[11] B. Horton, Soil Research, 50, 447 (2012)

[12] A.M. Grishin, N.V. Baranovskij, Journal of Engineering Physics and Thermophysics, 76, 166 (2003)

[13] J.-C. Valette, V. Gomendy, C. Houssard, D. Gillon, International Journal of Wildland Fire, 4, 225 (1994)

[14] M.V. Ulyanov, Informationnie tekhnologii, 11, 29 (2003) (In Russian)

[15] N.V. Baranovskiy, M.V. Zharikova, Lecture Notes in Geoinformation and Cartography - LNG\&C. Thematic Cartography for the Society 13 (2014)

[16] N.V. Baranovskiy, E.P. Yankovich, Proceedings of 5th International Conference on Cartography and GIS (Riviera, Bulgaria, 15-20 June 2014), 2, 756 (2014)

[17] E.P. Yankovich, N.V. Baranovskiy, $14^{\text {th }}$ International Multidisciplinary Scientific Geoconference SGEM - 2014. GeoConference on Informatics, Geoinformatics and Remote Sensing, 1, 607 (2014) (DOI: 10.5593/sgem2014B21)

[18] J. Pieticakainen, R. Hiukka, H. Fritze, Soil Biology and Biochemistry, 32, 277 (2000)

[19] T. Nkheloane, A.O. Olaleye, Soil Research, 50, 579 (2012)

[20] G.V. Kuznetsov, N.V. Baranovskiy, EPJ Web of Conferences, 76, (01028), 1 (2014) 